UNIVERSITY OF MINNESOTA

ST, ANTHONY FALLS HYDRAULIC LABORATORY

Project Report No. 77

\title{
A New Facility for Evaluation of Materials Subject to Erosion and Cavitation Damage
}

\author{
by \\ JOHN F. RIPKEN, JOHN M. KILLEN, \\ SCOTT D. CRIST \\ and \\ ROY M. KUHA
}

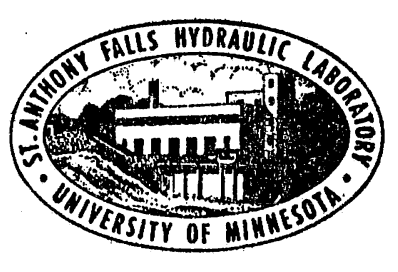

Prepared for

OFFICE OF NAVAL RESEARCH

and

DAVID TAYLOR MODEL BASIN

under

Bureau of Ships General Hydromechanics Research Program

S-R009-01-01

Contract Nonr 710(56), Task NR 062-334

March 1965

Minneapolis, Minnesota 
Reproduction in whole or in part is permitted for any purpose of the United States Government 
Despite the development of many devices for study of the failure of materials exposed to cavitation or fluid erosion, a need has existed for a facility which would permit a more fundamental study of the damage mechanism. Fundamental studies which can lead to naval design procedures providing reduced erosion are essential to modern naval interests.

Studies leading to the development of the new facility described herein were carried out at the St. Anthony Falls Hydraulic Laboratory during the period from January, 1964 to March, 1965 under the joint sponsorship of the David Taylor Model Basin and the Fluid Mechanics Branch of the Office of Naval Research. 
1
1
1
1

; 


\section{CONTENTS}

\section{Page}

Preface . . . . . . . . . . . . . . . . . . . . .

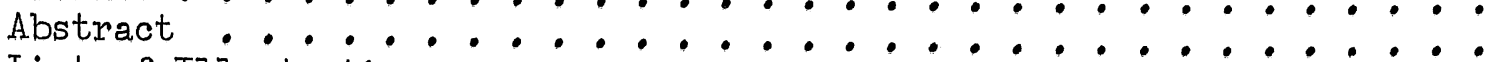

List of Illustrations

I. INTRODUCTION .......................

II. EXPERTMENTAL APPARATUS . . . . . . . . . . . .

III. EXPERTMENTAL PROCEDURE . . . . . . . . . . . . .

IV. PRELIMINARY FINDINGS . . . . . . . . . . . . . . .

V. CONCLUSTONS . . . . . . . . . . . . . . . . . 
LIST OF ILIUSTRATIONS

Figure

Page

I The Rotor Assembly . . . . . . . . . . .

2 A Mounted Test Specimen at the Rotor Tip . . . . . .

3 The Impact Damage Facility - Housing Chamber Closed . •

4 The Impact Damage Facility - Housing Chamber Open . . .

5 Weight Loss Damage for Various Materials and Exposures . .

6 Impact Damage, Aluminum Alloy 1100 F Annealed . . . .

7 Impact Damage, Stainless Steel Type 430 Annealed . . . .

8 Damage Rate Values for Stainless Steel Types 304 and

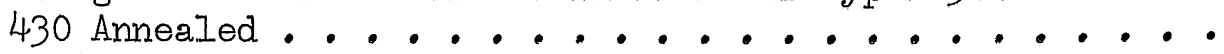

A Comparison of Impact Failure with Failure by a Standard Fatigue Method for 304 Stainless Steel . . . 
- 
A NEW FACILITY FOR EVALUATION OF MATERIALS

SUBJECT TO EROSION AND CAVITATION DAMAGE

\section{INTRODUCTION}

For nearly forty years various investigators have attempted to develop and routinely employ test procedures which would realistically evaluate the service resistance of fabricated materials exposed to erosion by water impact. These evaluations were necessary for the design selection of materials for steam turbine blades, for hydraulic machinery, and more recently for underwater ship appendages and for aircraft windshields.

Early studies of damage demonstrated the difficulties in attempting to make evaluations on the basis of field tests. As a result field testing has largely given way to simplified and accelerated testing in the laboratory. In the case of steam turbines this has been accomplished with whirling blades impacting high-speed jets. Studies of aircraft rain erosion have also used whirling blades in a spray and, for higher speeds, a projecting of fluid slugs at stationary solids or firing solids at stationary drops of liquid. For hydraulic devices and ship members exposed to cavitation, the accelerated test apparatus has varied widely, but three basic types have found considerable use. These are the Venturi throat or recirculating tunnel, the vibratory apparatus, and the submerged rotating disk with cavitating perforations.

Cavitation damage studies in the three named types of devices show a general similarity of findings, but a number of significant differences continue to appear in the quantitative values derived from the various test programs. The findings and differences in these studies have yielded a number of pertinent questions which include the following:

1. Is there a threshold value of the relative flow velocity at which damage begins on a given material; or is damage a combined function of the frequency and intensity of the impact being delivered as a result of the velocity?

2. Is there an "incubation" period of exposure during which little or no evident damage occurs but which is eventually followed by substantial erosion when the exposure condition persists?

3. Are there a number of cycles of increasing and decreasing rates of damage with time as observed 
by Hammitt [1] ${ }^{*}$ or is there a simpler, progressively increasing rate as observed by Lichtman et a. [2]? Are these later stages of damage simply a byproduct of the flow disturbances caused by the earlier stages and thus a function of the particular test environment? Should these later stages be omitted in a fundamental damage evaluation?

4. The rate of weight loss attributable to damage appears to be a function of some relative fluid velocity raised to the $n^{\text {th }}$ power. Is this power the fourth, fifth, sixth, or eighth as observed by various experimenters? Will the ultimate velocity limit of all shallow depth underwater naval operations be keyed to this relation?

5. To what extent can the elasticity, fatigue, hardness, strain energy, roughness, thickness, or other characteristics of the material be correlated with the observed damage? Will the strain energy correlation of Thiruvengadam [3] prove to have wide-ranging application or will additional properties be required in the correlation as suggested by Hammitt et a.I [4]?

6. To what extent do the density, viscosity, surface tension, chemical, or other characteristics of the fluid influence the damage?

While a study of the literature indicates a present ability to make suitable material selections for many design problems and provides partial or qualified answers to many of the foregoing questions, there is substantial evidence that:

\section{a. Naval operations will be continually plagued by cavitation problems as the trend toward increased speeds continues. \\ b. Existing types of damage facilities are inherent- ly incapable of providing suitable definition to the fundamental mechanism of cavitation damage.}

The prime difficulty with the existing test systems for accelerated cavitation damage lies in their inability to provide adequate experimental control over the many variables that are concurrently involved in the cavitation damage phenomenon. This suggests that the control problems might be greatly simplified by eliminating the complex and obscuring parts of the phenomenon that have to do with the creation of the cavity, and by concentrating instead on

\footnotetext{
* Numbers in brackets refer to the List of References on page 13.
} 
the erosion mechanism associated with cavity collapse. That this is a realistic approach is supported by the opinion of many investigators as summarized by Eisenberg [5] who shows evidence that the principal mechanism of cavitation damage is the mechanical destruction of the solid surface by the localized impact of the surrounding fluid.

The facility described herein strips the collapse phenomenon to its bare essentials by examining the erosion action of an impacting fluid element on a boundary solid. This is done in a system which minimizes the variables and establishes a good control of those which remain. This approach by no means discounts the importance of continued studies of the more complete cavitation model but instead aims to aid in clarifying the study of erosion or damage by concentrating on the most pertinent and fundamental elements of the mechanism.

That some simplification is possible may be seen from a study of previous steam turbine blade erosion tests and the windshield rain erosion tests which have employed fluid impact systems which are much simpler than those employed in cavitation studies. While gross fluid jet impact studies were used many years ago by Rheingans [6] to simulate cavitation damage for materials selection, the method was abandoned in favor of the seemingly simpler vibratory test. Abandonment was to a considerable extent based on a lack of evidence showing that cavitation damage is basically the product of a fluid jet impact erosion mechanism. Jet impact as a damage mechanism now appears to have some substance as a result of the work of Ellis, Naude, PIesset, and Mitchell [7][8][9] at the California Institute of Technology. The CalTech work has, by high-speed photography, served to show that cavities collapsing near boundaries collapse unsymmetrically with the formation of a reentrant jet or interface front which moves through the cavity to impinge on the solid boundary. The physical observations by Ellis have shown that the jet velocities are of a damaging order of magnitude and that the shape of the jet tip is probably significant to the pressure developed on the boundary.

Currently studies of damage on steam turbine blades are made with sample pins or blocks attached to the periphery of a disk rotating in air at high speed. A recent version of this type of facility has been employed also for material evaluations for cavitating hydraulic machinery [10]. In this type of test fluid impact is achieved on the sample by continuous injection of a high-speed water jet positioned with its axis parallel to the disk shaft and 
passing between the rotating damage samples. By this mechanism a fluid element of substantial mass impacts on the sample at high frequency (several hundred per second) and with high velocity (up to $1000 \mathrm{fps}$ ). The resulting damage rate is very high. The device has produced interesting results but is not considered suitab́le to fundamental studies because of an inherent inability to independently control the frequency and velocity of impact and to control the geometry of the jet front which initially impacts on the solid. The high damage rates in these tests quite probably relate to grossly abnormal thermal, chemical, or electrical effects as well as to high stressing. These secondary effects might be quite different for elastomers or plastics than they are formetals and must be brought under control in any fundamental study.

The windshield erosion studies have even further simplified the fluid impact test mechanism by either firing a solid sample at a stationary droplet [11] or by projecting (up to $4000 \mathrm{fps}$ ) a fluid slug at a stationary solid [12]. The first method has permitted some control of the shape and size of the fluid interface and of the impacting velocity but only in single impacts. It does not permit measurement of impact pressure transients. The second method permits measuring transient pressures in the solid but does not permit refined control of the jet size or shape because of the inherent instabilities of an interface under dynamic conditions. More important perhaps is the inability of these systems to produce the repetitive impacts which are basic to the fatigue failures which are believed fairly common with cavitation damage. These two methods together have, however, served many of the needs of rain erosion studies in that these studies are generally concerned with single impact failure for droplets impinging on thin plate structures at supersonic speeds.

The foregoing methods were not considered directly applicable to simulating cavitation damage, but they did serve to point the way to a modification which appears to be a workable compromise. This modification consisted of designing an apparatus in which a drop of slow moving water would impact on a small target of test material moving at a high velocity. The mass of the impacting liquid and the velocity of impact were to be rather readily and accurately controlled, and controlled rates of impact repetition were to be provided.

The resulting experimental equipment described herein produces many drops of water of a selected uniform size and introduces them into the path 
of a target of test material mounted on a rotating arm. The introduction of the drops into this path is controlled with precision to subject the same point on the target to repetitive blows at a selected impact speed.

\section{EXPERTMENTAL APPARATUS}

The basic facility consists of a rotor with a material specimen attached at the periphery in such a manner that there is impact with a column of liquid droplets during rotation of the specimen.

The aluminum alloy rotor as shown in Fig. I consists of two central disks supporting two projecting arms, the tips of which contain mounting sockets for the test specimen as shown in Fig. 2. The specimen rotates in a circle of $23.68 \mathrm{in}$. diameter at a present maximum rpm of 12,000 giving a tangential speed of 1,250 fps. (It is anticipated that future changes will permit increasing the speed to 1,500 fps or more.) Speed is infinitely adjustable down to the minimum values of interest of about $400 \mathrm{fps}$. The specimen has a target face of 1/4 in. diameter as shown in Fig. 2. A small target volume of about $1 / 8$ cc favors sensitive weight loss determinations. The tapered target is mounted in a tapered recess in the rotor arm and is drawn snug with a draw screw tapped into the rear of the target.

The rotor is spun within a protective chamber by a variable speed, directly connected, electric motor of $1 \mathrm{hp}$. The motor is a type commonly employed in vacuum cleaners. An auxiliary motor and blower are employed for cooling the drive motor. The general assembly is shown in Fig. 3 in the closed condition used for testing and in Fig. 4 in the open position used for changing test specimens.

The drive system is patterned after systems successfully employed with ultra-centrifuges [13]. The drive shaft is a 1/8 in. diameter stainless steel tube gripped by collets mounted on the motor shaft and on the rotor. The tube provides flexible coupling which permits the rotor to find its own center of rotation without elaborate dynamic balance procedures. This also permits a very smooth high-speed operation even after loss of target material. This stability is quite important for photographic purposes. It has been found possible to superimpose nearly 4000 exposures on a single film without loss in desirable sharpness of the target or drop. 
The equipment' was adjusted so that the center of the sample face would impact a liquid drop on each revolution. Four test speeds were arbitrarily selected at $500,750,1000$, and 1250 fps.

A simple measure of weight loss as affected by exposure time was made by stopping the apparatus periodically and removing and weighing the sample. It was possible to watch the progress of the erosion visually with a small telescope. This was of great help in establishing the increment of exposure time in a test run.

\section{PRELIMTNARY FINDINGS}

The four materials which were exposed to weight loss damage tests have physical properties briefly summarized as follows:

aluminum type 1100F annealed, ultimate strength 13,000 psi, Brin. hard 23

cast iron "as cast"

stainless steel type 430, annealed, ultimate strength 70,500 psi, Brin. hard 152

Stainless steel type 304 cold drawn, annealed, ultimate strength 90,000 to 125,000 psi

A graphical summary of the weight loss tests on these four materials is shown in Fig. 5.

The general character of the damage inflicted on a test specimen is shown in photographs taken at the completion of a test series. Figure 6 shows for the aluminum alloy in part (a) the results at $500 \mathrm{fps}$. Part (b) shows the results for $750 \mathrm{fps}$ and part (c) for $1000 \mathrm{fps}$. The photos demonstrate plastic flow with considerable uplift deformation at the edge of the impact region. Part (a) shows impact positioning fairly well confined whereas part (b) shows some wandering of impact around a deep central hole. Part (c) again shows a condition of some wandering about the deep central hole and additionally shows a large area of secondary erosion by spray following the initial impacting. Visual studies of the impacting droplet indicate that with a smooth surface the droplet spreads slightly radially on the target face and then rebounds in a spray which moves radially outward and away from the face. This spray evidently moves fast enough so that it clears the target sweep path without again striking the target. However, as shown in Fig. 6(c) the spray rebounding from a highly roughened surface moving at 1000 fps does make a second damaging impact. 
The half hour impact tests on the type 430 stainless steel failed to show any weight loss with an impact velocity of 500 fps but. yielded the data of Fig. 5 at 750 and 1000 fps. The photos of Fig. 7. show a very slight evidence of plastic deformation. It is noteworthy that the last points on the weight loss curve of Fig. 5 for a velocity of 1000 fps showed a punching through of the target specimen which was approximately 1/16 in. thick at the impact point. It is interesting to note that the diameter of the large outer end of this hole as shown in Fig. $7(b)$ is approximately the diameter of the impacting droplets $(0.047$ in.).

The impact tests on the type 304 stainless steel were run at 1000 and 1250 fps with weight loss results as shown in Fig. 5. Photographs of these specimens are not included but have a considerable resemblance to those of the 430 stainless steel shown in Fig. 7. The major difference between the 304 and 430 alloys in Fig. 5 is the substantial "incubation" or delay time before weight loss occurs with the 304 a.lloy.

Thiruvengadam and Preiser [16] outlined four zones of cavitation damage, based on vibratory tests, which also seem applicable to impact erosion damage. These zones which are evaluated in terms of weight loss per unit of time are described as:

Zone 1. An incubation or no weight loss zone. In cavitation tests with a vibratory apparatus this was shown to depend on amplitude for a given frequency.

Zone 2. Accumulation zone. A zone in which the energy absorption rate increases with time resulting in increasing loss of material with increasing test duration.

Zone 3. Attenuation zone. The rate of weight loss reaches a peak value and begins to decrease. This zone is reported to be characterized by the formation of isolated deep craters on the surface of the test material indicating that the attenuation of energy absorption is associated with the influence of the craters on the bubble collapse process.

Zone 4. Steady state zone. The rate of weight loss. reaches a constant value.

These four zones are not directly identified in the accumulated weight loss type of plotting used in Fig. 5 but can be distinguished in an alternate plotting using weight loss per unit time. An alternate plot of this type for data relating to the 304 and 430 stainless steel is shown in Fig. 8. The plotting of Fig. 8 serves to show the same general form as weight loss data 
from other types of facilities as summarized by Thiruvengadam and Preiser [16]. However, despite this similarity there is reason to question their use of zone 4 damage rates as the most useful index of a material's resistance. Actually, only the time or rate values of zone 1 and zone 2 are directly associated with the material characteristics whereas the values of zones 3 and 4 additionally involve the overriding influence of the progressive cratering. Since the local cratering environment differs for each type of test facility and for every prototype application, there is little reason to believe that zone 4 evaluations will be meaningful in an absolute sense. In consequence this suggests that future impact damage or cavitation damage tests should give prime emphasis to damage values relating to zones 1 and 2 .

There is some indication in the limited test data of Fig. 5 that meaningful damage evaluations can be derived from zone 1 for an impact type of facility. This is based on the fact that the facility can produce controlled impact conditions which are subject to a fairly rational analysis of the resulting loading and that controlled numbers of load cycling can be applied. In short, this concept is one of fatigue failure in which some combination of stress value and cycles of application determines the failure.

This concept is given some substance if the data of Fig. 5 for the 304 stainless steel are converted to values of stress and cycles of stress. The cycles of stress to failure may be evaluated by assuming that failure occurs where the horizontal line representing zone 1 intersects the sloping line representing zone 2. For the 304 stainless with an impact velocity of 1000 fps the intercept occurs at a time equivalent to $8.6 \times 10^{4}$ cycles and for a velocity of $1250 \mathrm{fps}$ at $1.7 \times 10^{4}$ cycles.

The value of the peak impact pressure stress may be roughly approximated by the expression $p=\alpha p c v$ employed many years ago by Ackeret and deHaller and given more recent consideration by Engels [17]. In this expression $\alpha$ is an arbitrary constant which approximates and is assumed to be unity, $\rho$ is the water density or 1.94, $c$ is the acoustic velocity which is assumed as $4800 \mathrm{fps}$, and $v$ is the relative velocity of impact. With this the $v$ value of 1000 fps yields $p=32 \times 10^{3}$ psi and the $v$ value of 1250 fps yields $p=40 \times 10^{3}$ psi. The equivalent value for the no damage test which was run at $v=750$ fps yields $p=24.2 \times 10^{3}$ psi. 
The foregoing stress-cycles values are plotted in Fig. 9 together with longitudinal fatigue failure test values for an annealed 304 stainless steel as given in Ref. [18]. The relative agreement of these different types of test data may perhaps be fortuitous but is nevertheless encouraging in a preIiminary experiment.

\section{CONCLUSIONS}

The equipment developed under this contract has shown a capability of eroding many typical structural materials by impact of a small liquid drop. It has the capability of repetitive impact on a sma.17 area of sample material under precise control of droplet mass and velocity.

The pattern of weight loss damage in tests with the impact facility shows a distinct similarity to weight loss values obtained from cavitation type test facilities.

Limited tests with ductile materials show marked deformation prior to loss of weight. More detailed tests with this apparatus can serve to more clearly define the transition from plastic flow to actual loss of material and the extent to which plastic flow may occur in the "incubation" period of harder materials.

The "incubation" period as defined earlier in this report and as evidenced in the tests with a self-hardening material has been shown to be a region capable of refined study with this type of apparatus. This is a particularly important region, for it serves to define the conditions under which a desirable type of material may be expected to fail. Preliminary findings indicate that failure represented by the limit of "incubation" may be rather directly associated with the better known fatigue failure properties of the material. 
IIST OF REFERENCES

[I] Hammitt, F. G., Observations on Cavitation Damage in a Flowing System, University of Michigan, Technical Report 03424-4-T, June 1962.

[2] Lichtman, J. Z., Kallas, D. H., Chattan, C. K., and Cochran, E. P. Jr., "Study of Corrosion and Cavitation Erosion Damage," Transactions A.SME, Vol. 80, August 1959.

[3] Thiruvengadam, A., "A Unified Theory of Cavitation Damage," ASME Paper No. 62-Wa-118, 1962 .

[4] Hammitt, F. G. et al, "Initial Phases of Damage to Test Specimens in a Cavitating Venturi," A.SME Paper No. 64-WA/FE-2, 1964.

[5] Eisenberg, P., Cavitation Damage, Hydronautics, Inc., Technical Report 233-1, December 1963.

[6] Rheingans, W. J., Prevention and Reduction of Cavitation and Pitting in Hydraulic Turbines, Allis Chalmers Engineering Bulletin No. 11, 1949.

[7] Plesset, M. S. and Mitchell, T. P., "On the Stability of the Spherical Shape of a Vapor Cavity in a Liquid," Quarterly of Applied Mathematics, Vol. 13, 1956.

[8] Naude, C. F. and Ellis, A. T., "On the Mechanism of Cavitation Damage by Nonhemispherical Cavities Collapsing in Contact with a Solid Boundary," Transactions ASME, Vol. 83, Series D, December 1961.

[9] Ellis, A. T., Slater, M. E., and Fourney, M. E., "Some Flow Approaches to the Study of Cavitation," IAHR Symposium on Cavitation and Hydraulic Machinery, Sendai, Japan, September 1962.

[10] Hobbs, J. M., "Problems of Predicting Cavitation Erosion from Accelerated Tests," ASME Paper No. 61-HYD-19, 1961.

[1]] Jenkins, D. C., "Erosion of Surfaces by Liquid Drops," Nature, Vol. 176, August 13, 1955.

[12] Brunton, J. A., "Deformation of Solids by Impact of Liquids at High Speeds," ASTM Symposium on Erosion and Cavitation, June 1961.

[13] Weissburger, A., Physical Methods of Organic Chemistry, Interscience, 1949.

[14] Schneider, J. M. and Hendricks, C. D., "Source of Uniform-Sized Liquid Droplets," Review of Scientific Instruments, Vol. 35, No. 10, October 1964.

[15] Sweet, R. G., "High-Frequency Oscillography with Electrostatically Deflected Ink Jets," Stanford Electronics Laboratories, March 1964. 
[16] Thiruvengadam, A. and Preiser, H. S., On Testing Materials for Cavitation Damage Resistance, Hydronautics, Inc., Technical Report 233-3, December 1963.

[17] Engle, O. G., "Waterdrop Collisions with Solid Surfaces," Journall of Research for the National Bureau of Standards, Vol. 54, May 1955.

[18] Anonymous, Metals Handbook, American Society for Metals, 8th Edition, 1961, p. 4.19 . 
$\underline{\underline{F}} \underline{\underline{G}} \underline{\mathrm{U}} \underline{\mathrm{R}} \underline{\mathrm{E}} \underline{\mathrm{S}}$

(1 throungh 9) 



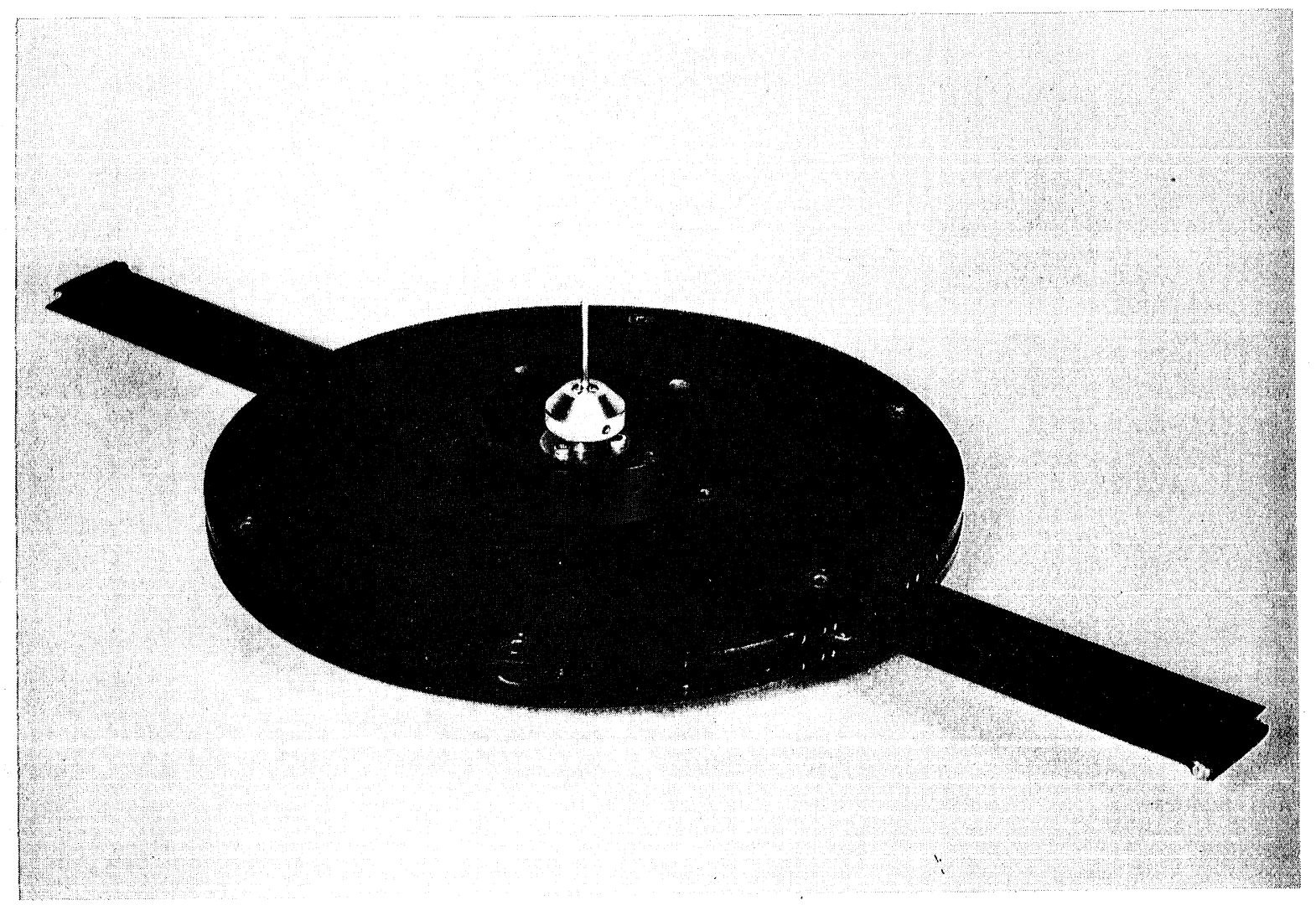

Fig. 1 - The Rotor Assembly

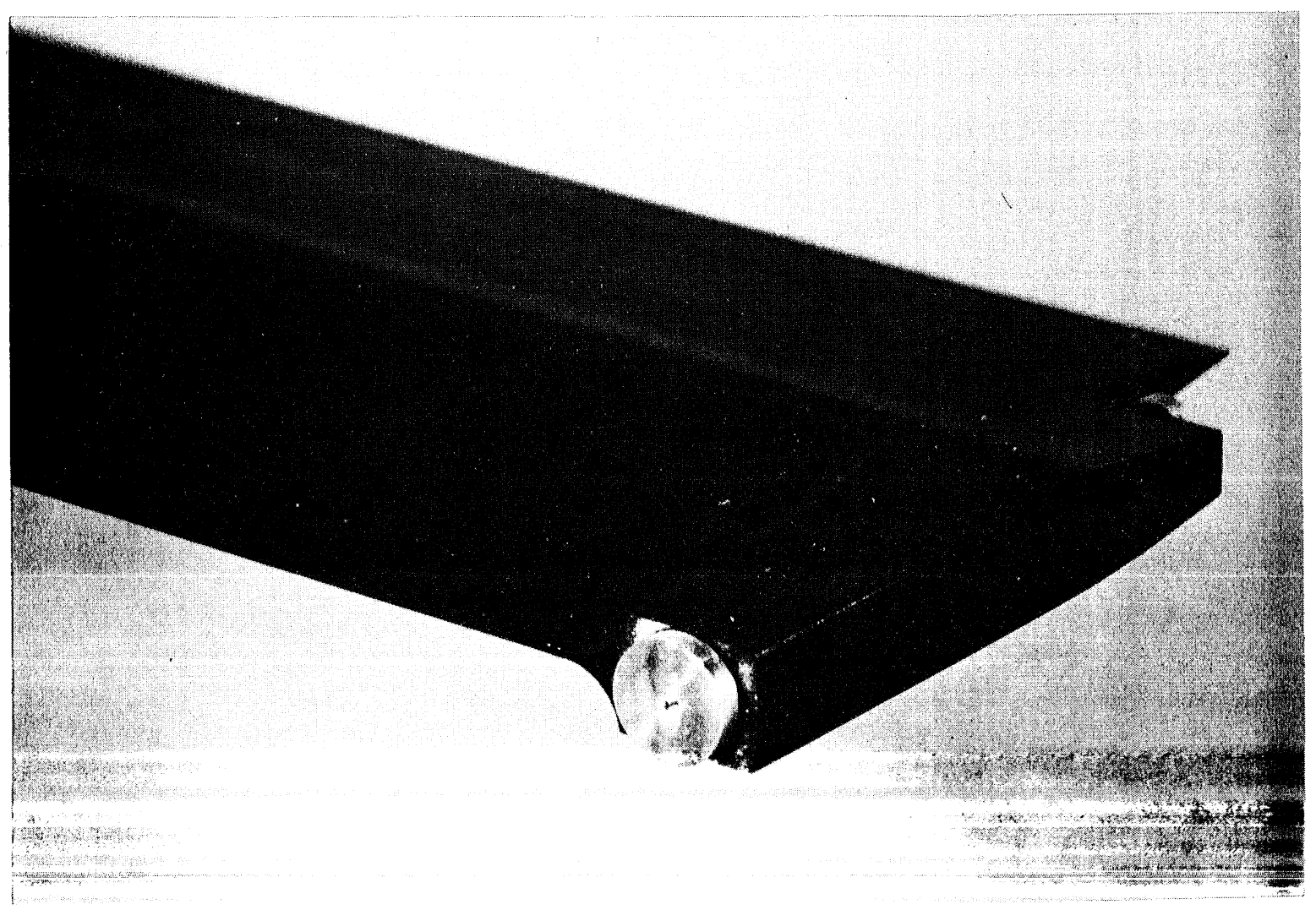

Fig. 2. - A Mounted Test Specimen at the Rotor Tip 


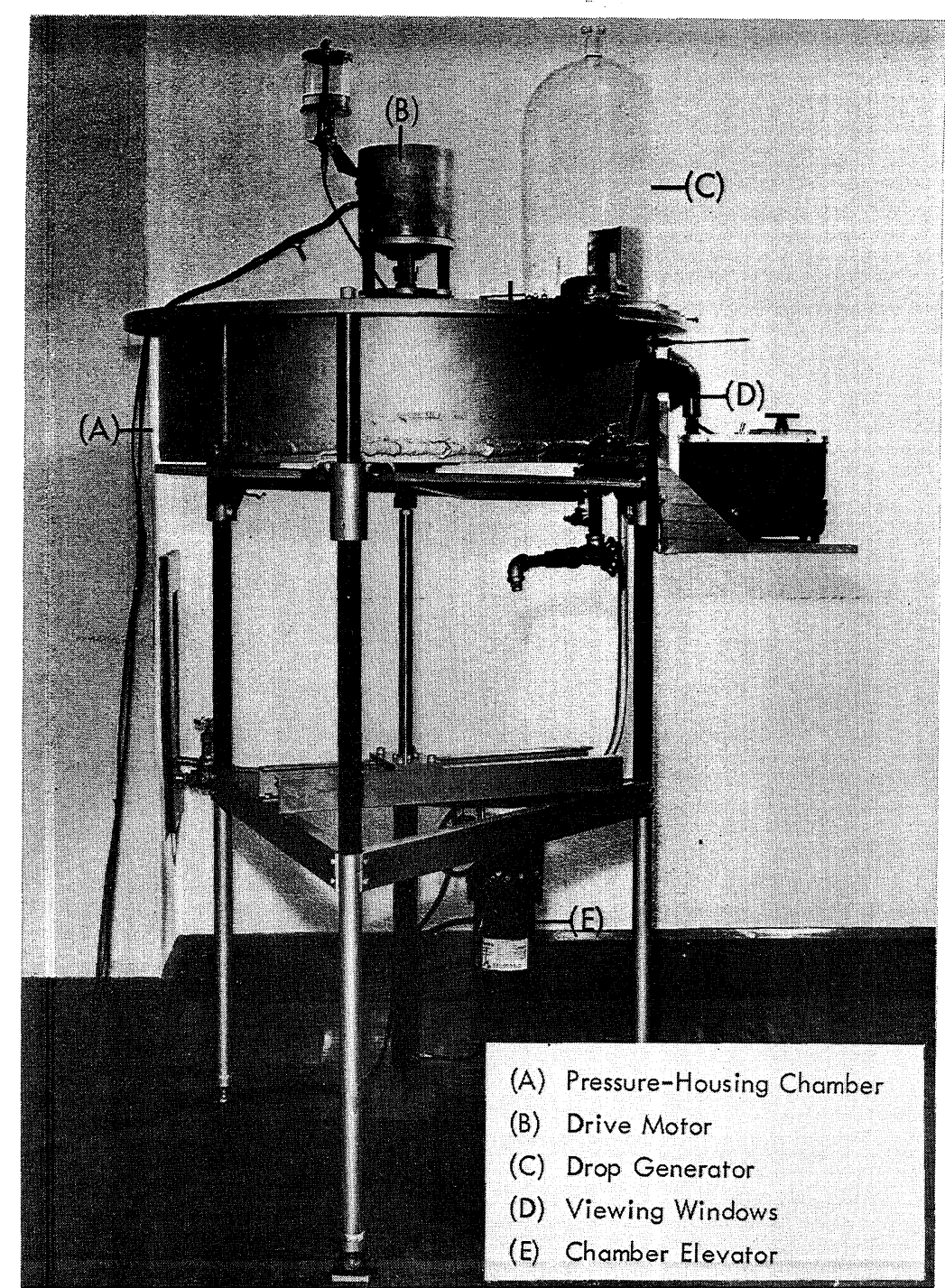

Fig。 3 - The Impact Damage Facility - Housing Chamber Closed

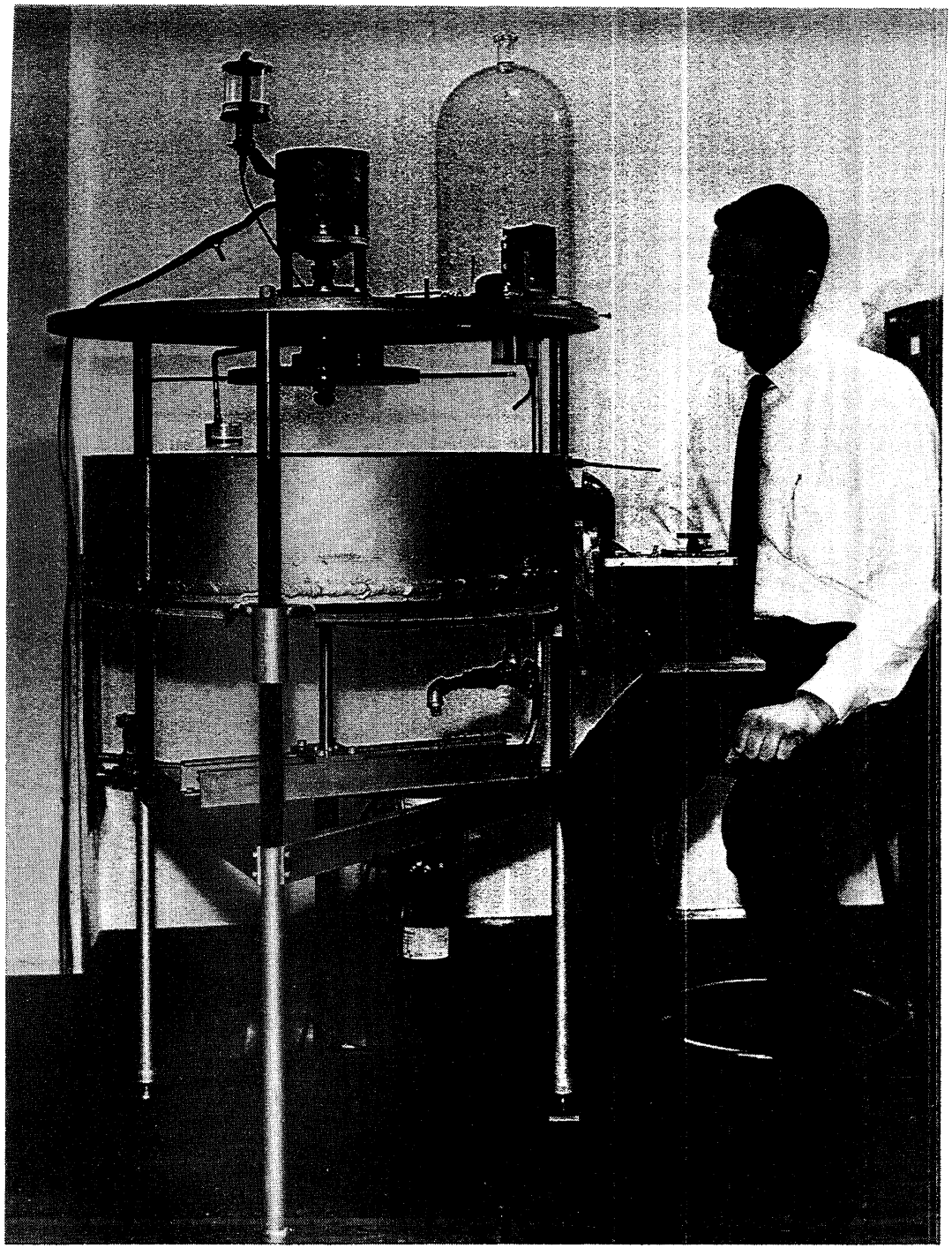

Fig. 4 - The Impact Damage Facility - Housing Chamber Open 


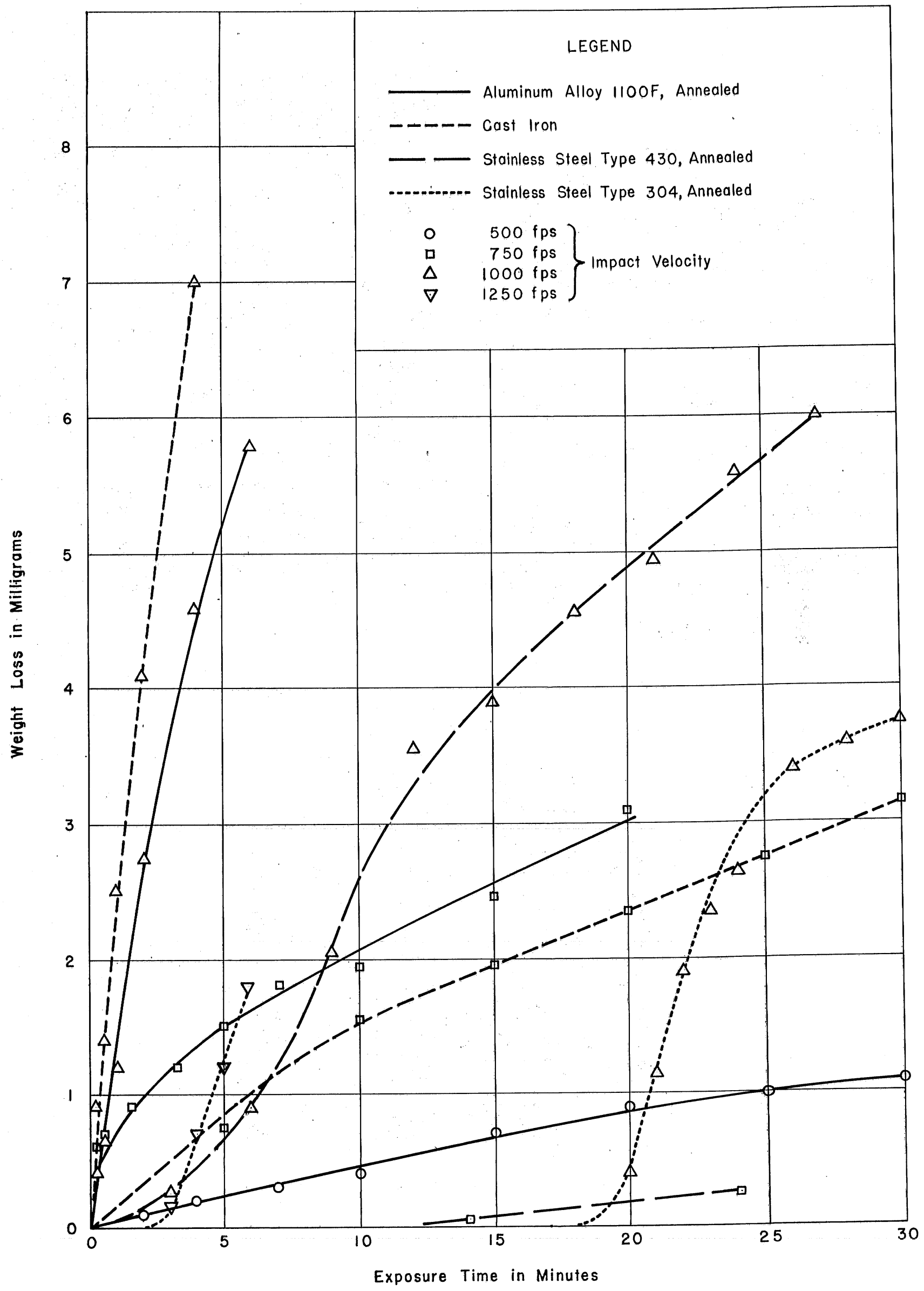

Fig. 5 - Weight Loss Damage for Various Materials and Exposures 


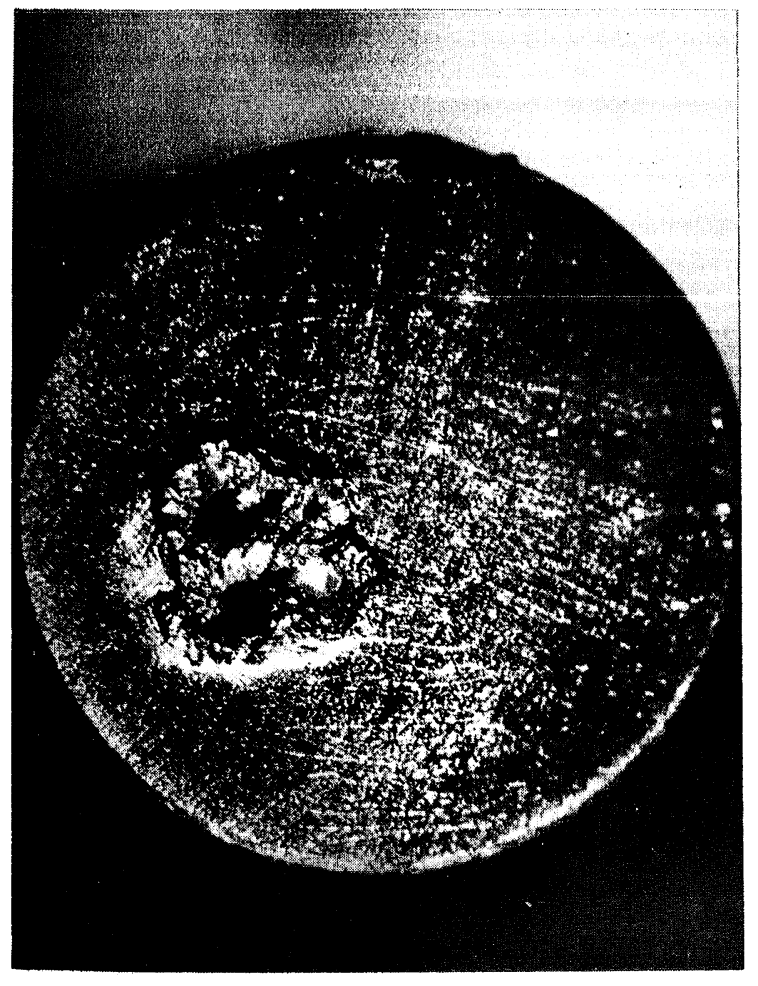

(a) Velocity $=500 \mathrm{fps}$, Time $=30 \mathrm{~min}$

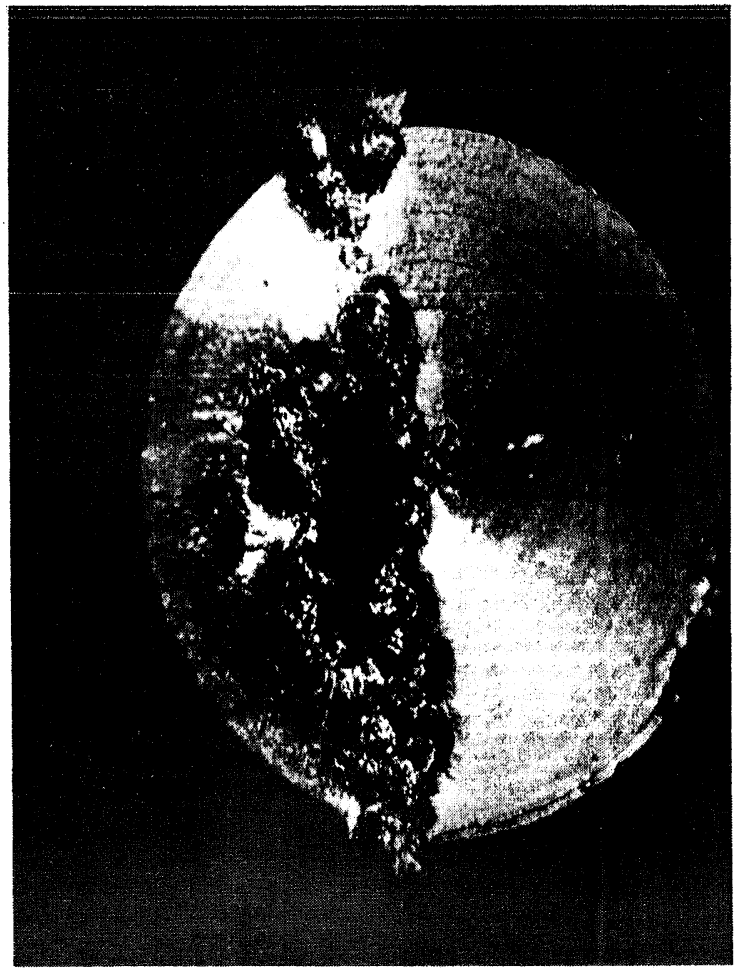

(b) Velocity $=750 \mathrm{fps}$, Time $=20 \mathrm{~min}$

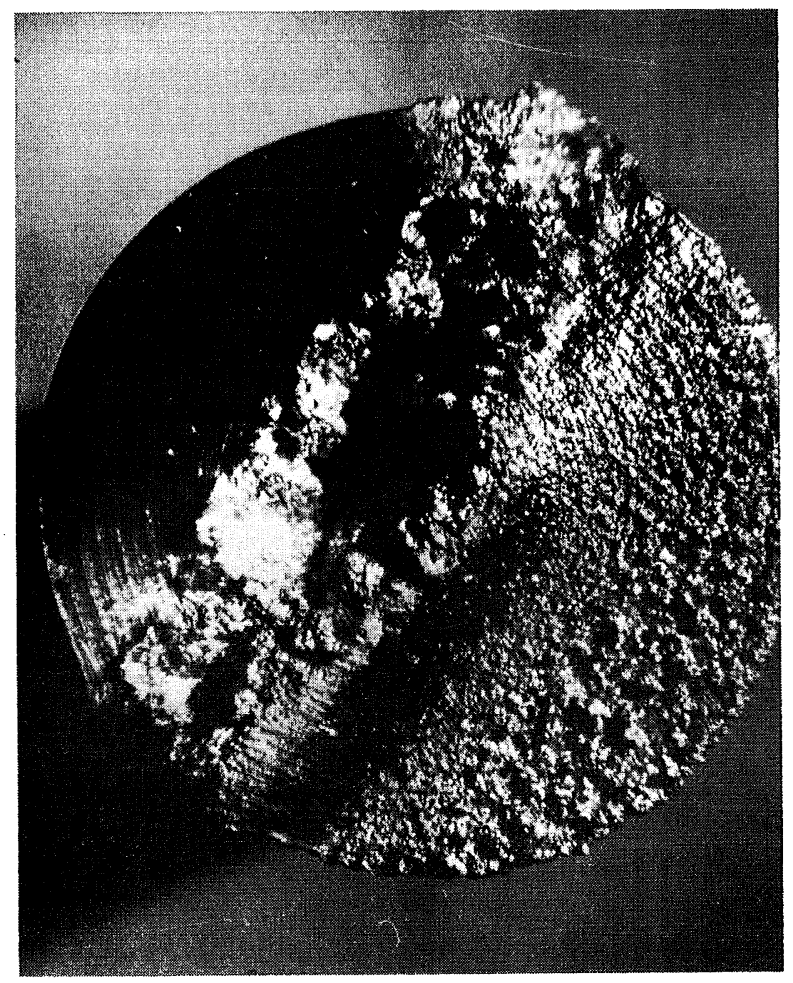

(c) Velocity $=1000 \mathrm{fps}$, Time $=6 \mathrm{~min}$

Fig.6 - Impact Damage, Aluminum Alloy 1100 F Annealed 


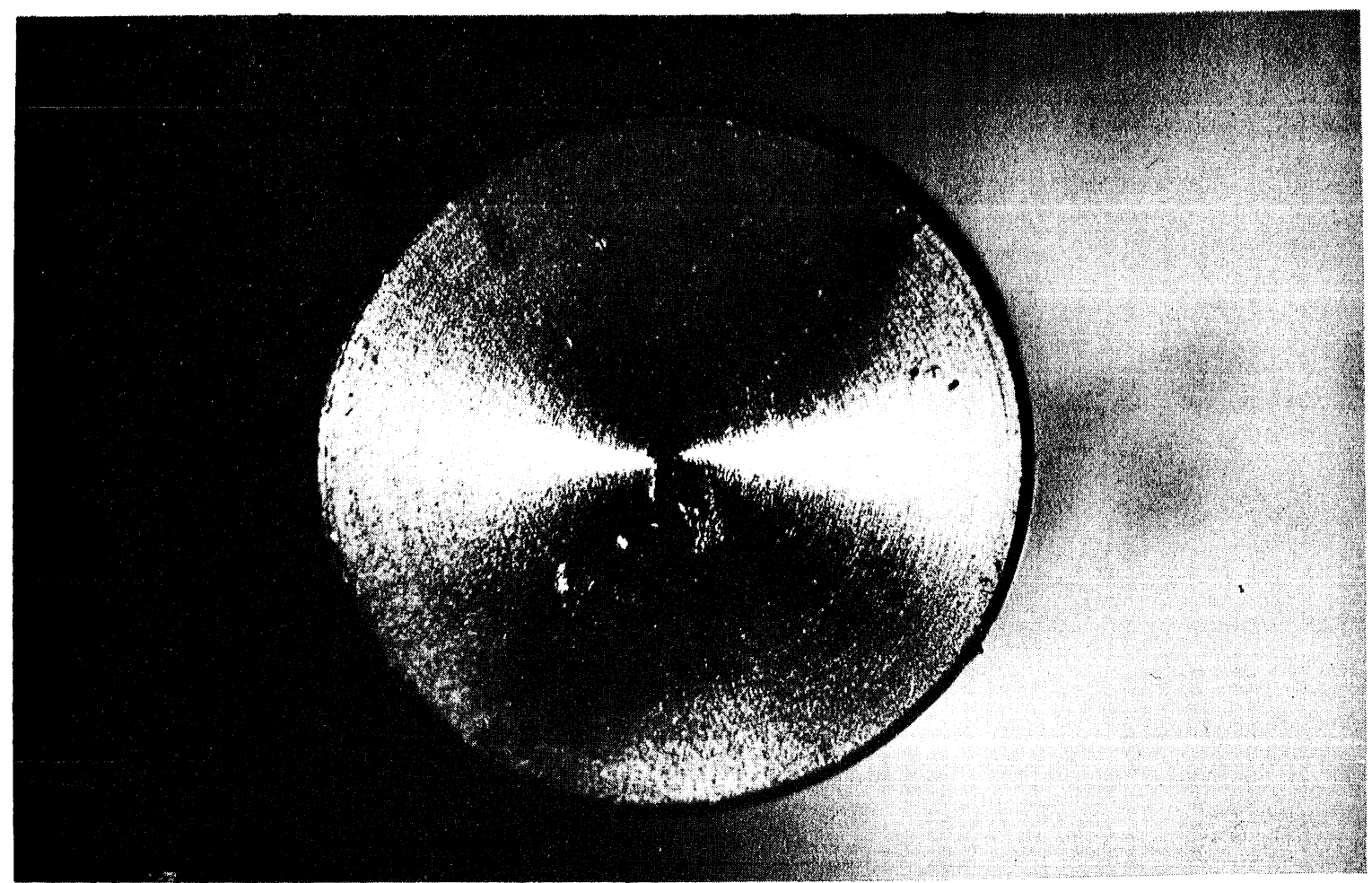

(a) Velocity $=750 \mathrm{fps}$, Exposure Time $=24 \mathrm{~min}$

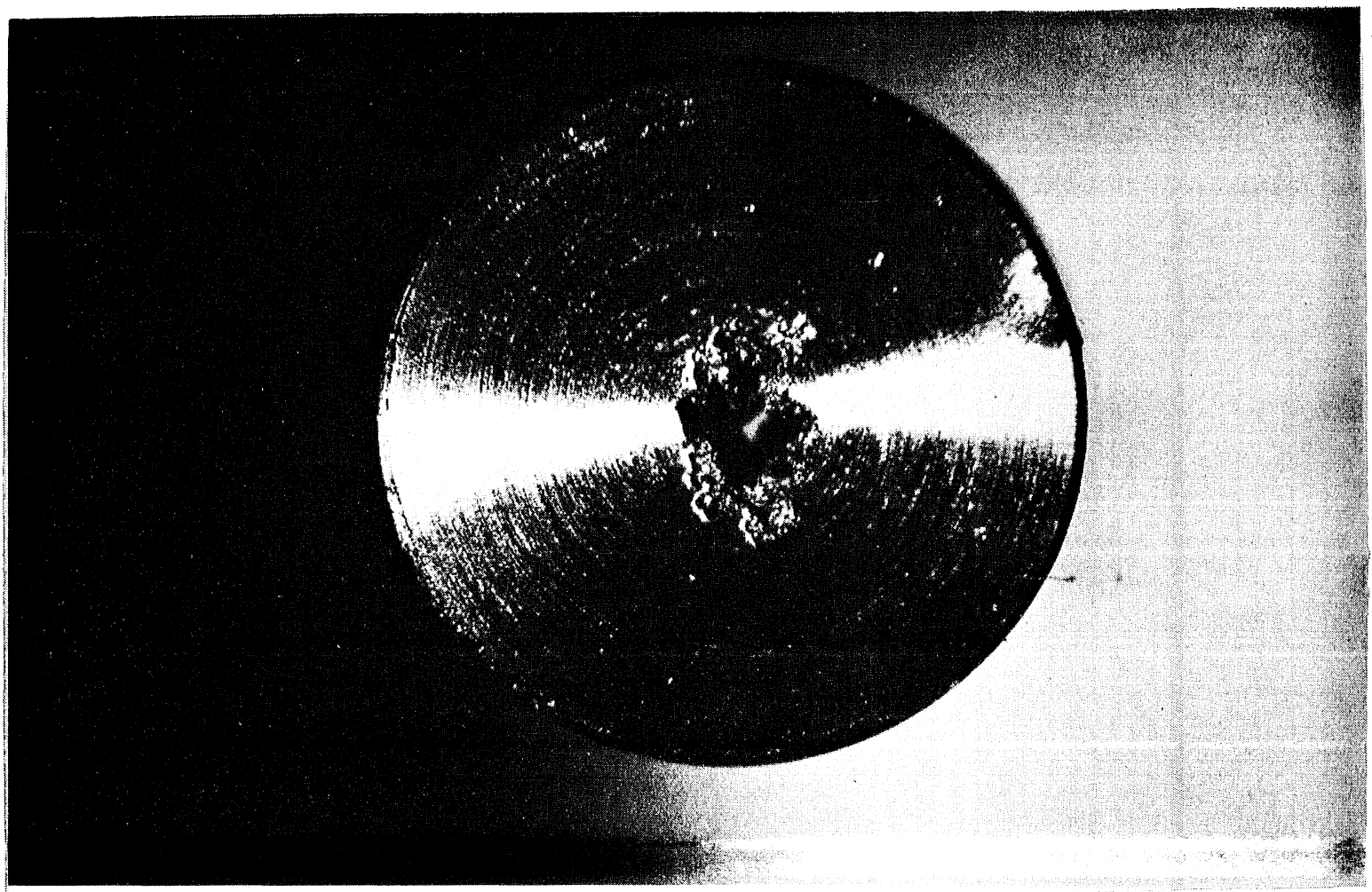

(b) Velocity $=1000 \mathrm{fps}$, Exposure Time $=27 \mathrm{~min}$

Fig. 7 - Impact Damage, Stainless Steel Type 430 Annealed 


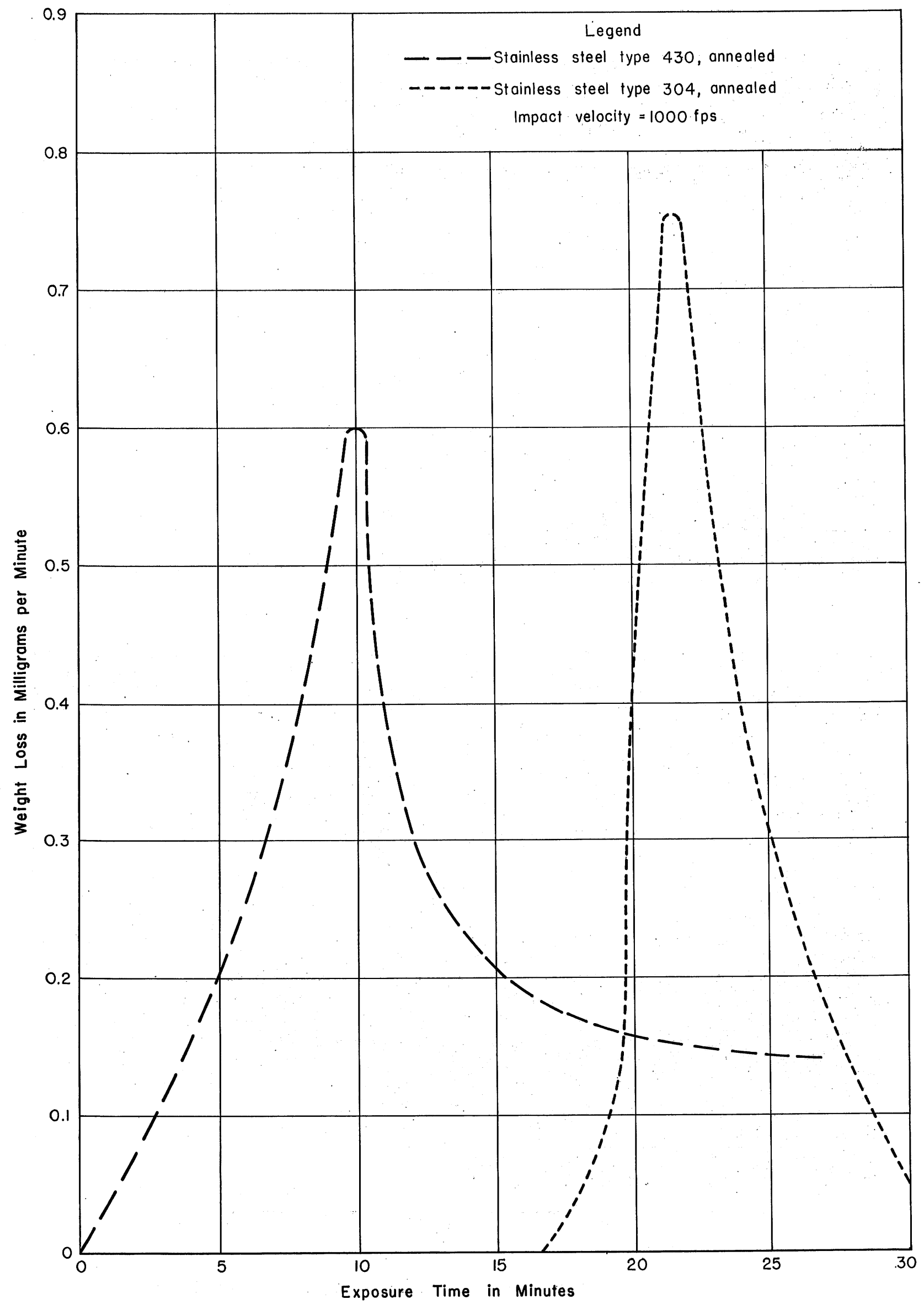

Fig. 8 - Damage Rate Values for Stainless Steel Types 304 and 430 Annealed 


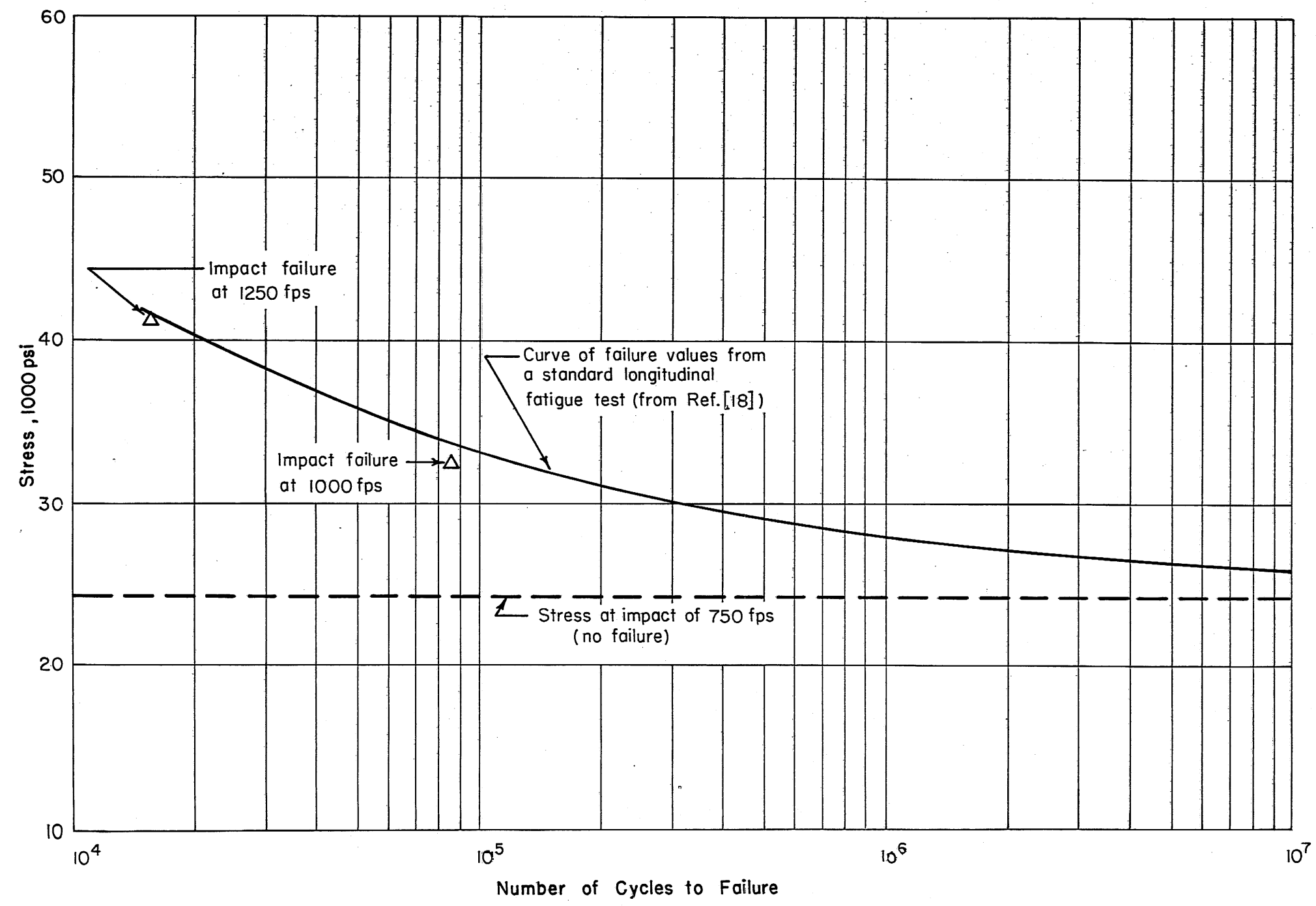

Fig. 9 - A Comparison of Impact Failure with Failure by a Standard Fatigue Method for 304 Stainless Steel 



\section{DISTRIBUTION LIST FOR PROJECT REPORT NO. 77 of the St. Anthony Falls Hydraulic Laboratory.}

Copies

6
Organization

Chief of Naval Research, Department of the Navy, Washington, D. C. 20360, Attn:

3 - Code 438

1 - Code 46.1

1 - Code 463

1 - Code 429

1. Commanding Officer, Office of Naval Research, Branch Office, 495 Summer Street, Boston 10, Massachusetts.

1. Commanding Officer, Office of Naval Research, Branch Office, 219 S. Dearborn St., Chicago, Illinois 60604.

I Commanding Officer, Office of Naval Research, Branch Office, 307 West 24th Street, New York 11, New York.

25 Commanding Officer, Office of Naval Research, Branch Office, Navy No. 100, Box 39, Fleet Post Office, New York, New York.

1 Commanding Officer, Office of Naval Research, Branch Office, 1030 East Green Street, Pasadena 1, California.

1 Commanding Officer, Office of Naval Research, Branch Office, 1000 Geary Street, San Francisco 9, California.

8 Director, Naval Research Laboratory, Washington, D. C. 20360, Attn:

1 - Code 2000

1 - Code 2020

6 - Code 2027

10 Chief, Bureau of Ships, Department of the Navy, Washington, D. C. 20360, Attn:

1 - Code 300

1 - Code 305

1 - Code 335

1 - Code 34.1

1 - Code 342A

1 - Code 345

1 - Code 421

1 - Code 440

1 - Code 442

1 - Code $634 \mathrm{~A}$

6 Chief, Bureau of Naval Weapons, Department of the Navy, Washington, D. C. 20360, Attn:

$I$ - Code R

1 - Code R-12 
1 - Code RR

I - Code RRRE

1 - Code RU

1 - Code RUTO

3 Chief, Bureau of Yards and Docks, Department of the Navy, Washington, D. C. 20360, Attn:

1 - Code D-202

1 - Code D-400

1 - Code D-500

25 Commanding Officer and Director, David Taylor Model Basin, Washington 7, D. C., Attn: Code 513.

4 Commander, Naval Ordnance Laboratory, Silver Spring, Maryland, Attn:

1 - Dr. A. May

1 - Desk DA

1 - Desk HL

1 - Desk DR

4 Commander, Naval Ordnance Test Station, China Lake, California, Attn:

1 - Mr. J. W. Hicks

1 - Code 5014

1 - Code 4032

1 - Code 753

6 Commander, U. S. Naval Ordnance Test Station, Pasadena Annex, 3202 E. Foothill Boulevard, Pasadena 8, California, Attn:

1 - Dr. J. W. Hoyt

1 - Research Division

1 - Code P508

1 - Code P804

1 - Code P807

1 - Code P80962 (Iibrary Section)

1 Hydrographer, U. S. Navy Hydrographic Office, Washington, D. C. 20360.

1 Superintendent, U. S. Naval Academy, Annapolis, Maryland, Attn: Library.

1 Commanding Officer and Director, U. S. Navy Marine Engineering Laboratory, Annapolis, Maryland, Attn: Code 750.

2 Commander, U. S. Naval Weapons Laboratory, Dahlgren, Virginia, Attn:

1 - Technical Library Division

1 - Computation and Exterior Ballistics Laboratory (Dr. Hershey) 
Copies

Organization

I. Commanding Officer, NROTC and Naval Administrative Unit, Massachusetts Institute of Technology, Cambridge 39, Massachusetts.

1 Commanding Officer and Director, Underwater Sound Laboratory, Fort Trumbul., New London, Connecticut, Attn: Technical Iibrary.

1 Commanding Officer and Director, U. S. Navy Mine Defense Laboratory, Panama City, Florida.

1 Superintendent, U. S. Naval Postgraduate School, Monterey, California, Attn: Library.

1 Commanding Officer and Director, Naval Electronic Laboratory, San Diego 52, Ca,ifornia, Attn: Code 4223.

1. Commanding Officer and Director, U. S. Naval Civil Engineering Iaboratory, Port Hueneme, California.

1 : Mr. J. Lichtman, U. S. Navy Applied Sciences Laboratory, New York Naval Shipyard, Brooklyn 1, New York.

1 Commander, Norfollk Naval Shipyard, Portsmouth, Virginia.

I Commander, New York Naval Shipyard, Naval Base, Brooklyn, New York.

1. Commander, Boston Naval Shipyard, Boston 29, Massachusetts.

I Commander, Philadelphia Naval Shipyard, Naval Base, Philadelphia 12, Pennsylvania.

I Commander, Portsmouth Naval Shipyard, Portsmouth, New Hampshire, Attn: Design Division.

I Commander, Charleston Naval Shipyard, U. S. Naval Base, Charleston, South Carolina.

1 Commanding Officer, U. S. Naval Underwater Ordnance Station, Newport, Rhode Island, Attn: Research Division.

I Commander, Long Beach Naval Shipyard, Long Beach 2, California.

1 Commander, Pearl Harbor Naval Shipyard, Navy No. 128, Fleet Post Office, San Francisco, California.

I Commander, San Francisco Naval Shipyard, San Francisco 24, California.

I Commander, Mare Island Naval Shipyard, Vallejo, California. 
Superintendent, U. S. Merchant Marine Academy, Kings Point, Long Island, New York, Attn: Department of Engineering.

1 Commandant, U. S. Coast Guard, 1300 E Street, N.W., Washington, D. C.

1 Beach Erosion Board, U. S. Army Corps of Engineers, Washington, D. C. 20360 .

1 Commanding Officer, U. S. Army Research Office, Box CM, Duke Station, Durham, North Carolina.

1 Commander, Hdqs. U. S. Army Transportation Research and Development Command, Transportation Corps, Fort Eustis, Virginia.

Director, U. S. Army Engineering Research and Development Laboratories, Fort Belvoir, Virginia, Attn: Technical Documents Center.

Defense Documentation Center, Cameron Station, Alexandria, Virginia.

Maritime Administration, 441 G Street, N.W., Washington, D. C. 20360, Attn:

1 - Coordinator of Research

1 - Division of Ship Design

1 Fluid Mechanics Section, National Bureau of Standards, Washington, D. C. 20360 , Attn: Dr. G. B. Schubauer.

1 U. S. Atomic Energy Commission, Technical Information Service Extension, P. 0. Box 62, Oak Ridge, Tennessee.

1 Director of Research, Code RR, National Aeronautics and Space Administration, 600 Independence Avenue, SW, Washington, D. C. 20546.

1 Director, Langley Research Center, National Aeronautics and Space Administration, Langley Field, Virginia.

1 Director, Ames Research Laboratory, National Aeronautics and Space Administration, Moffett Field, California.

1 Director, Lewis Research Center, National Aeronautics and Space Administration, Cleveland, Ohio.

1 Director, Engineering Science Division, National Science Foundation, Washington, D. C.

1 Commander, Air Force Cambridge Research Center, 230 Albany Street, Cambridge 39, Massachusetts, Attn: Geophysical Research Library.

1 Air Force Office of Scientific Research, Mechanics Division, Washington, D. C. 20360. 
Copies

Organization

1 National Academy of Sciences, National Research Council, 2101 Con- " stitution Avenue, NW, Washington, D. C. 20360.

1 Engineering Societies Library, 29 West 39th Street, New York 18, New York.

1 Society of Naval Architects and Marine Engineers, 74 Trinity Place, New York 6, New York.

I Webb Institute of Naval Architecture, GIen Cove, Long Isiand, New York, Attn:

1 - Professor E. V. Lewis

1 - Technical Library

3 The Johns Hopkins University, Baltimore 18, Maryland, Attn:

1 - Professor S. Corrsin

I - Professor F. H. Clauser

1 - Professor 0. M. Phillips

1 Director, Applied Physics Laboratory, The Johns Hopkins University, 8621 Georgia Avenue, Silver Spring, Maryland.

1 Professor John J. Foody, Chairman, Engineering Department, State University of New York, Maritime College, Bronx, New York 10465.

5 California Institute of Technology, Pasadena 4, California, Attn:

1 - Hydrodynamies Laboratory

1 - Professor T. Y. Wu

1 - Professor A. Ellis

1 - Professor A. Acosta

1 - Professor M. Plesset

7 University of California, Berkeley 4, California, Attn:

1 - Department of Engineering

1 - Professor H. A. Schade

1 - Professor J. Johnson

1 - Professor J. V. Wehausen

I - Professor E. V. Laitone

1 - Professor P. Lieber

I - Professor M. Holt

2 University of California, Los Angeles, California, Attn:

1 - Professor R. W. Leonard

1 - Professor A. Powell

1 Director, Scripps Institution of Oceanography, University of California, La Jolla, California.

1 Director, Alden Hydraulic Laboratory, Worcester Polytechnic Institute, Worcester, Massachusetts. 
Copies

Organization

Iowa Institute of Hydraulic Research, State University of Iowa, Iowa City, Iowa, Attn:

1 - Professor H. Rouse

1 - Professor I. Landweber

1 - Professor P. G. Hubbard

Harvard University, Cambridge 38, Massachusetts, Attn:

I - Professor G. Birkhoff

1 - Professor S. Goldstein

University of Michigan, Ann Arbor, Michigan, Attn: Engineering Research Institute.

Dr. George F. Wislicenus, Garfield Thomas Water Tunnel, Ordnance Research Iaboratory, The Pennsylvania State University, Post Office Box 30, University Park, Pennsylvania 16801.

St. Anthony Fa.1ls Hydraulic Laboratory, Mississippi River at 3rd Avenue S.E., Minneapolis, Minnesota 55414, Attn:

1 - Professor E. Silberman, Acting Director

1 - Professor J. F. Ripken

1 - Professor C. E. Bowers

1. - Mr. J. M. Wetzel

Department of Mechanical Engineering, University of Minnesota, Minneapolis 14, Minnesota, Attn: Professor E. R. G. Eckert.

Massachusetts Institute of Technology, Cambridge 39, Massachusetts, Attn:

1 - Professor P. Mandel

1 - Professor M. A. Abkowitz

Institute for Fluid Mechanics and Applied Mathematics, University of Maryland, College Park, Maryland, Attn: Professor J. M. Burgers.

Cornell Aeronautical Laboratory, Buffalo 21, New York, Attn: Mr. W. F. Milliken, Jr.

Brown University, Providence 12, Rhode Island, Attn:

1 - Professor Fred Bisshopp

1 - Dr. W. H. Reid

4 Stevens Institute of Technology, Davidson Laboratory, Hoboken, New Jersey, Attn:

1 - Mr. D. Savitsky

1 - Dr. J. P. Breslin

1 - Dr. D. N. Hu

1 - Dr. S. J. Lukasik

1 Director, Woods Hole Oceanographic Institute, Woods Hole, Massachusetts. 
5 Stanford University, Stanford, California, Attn:

1 - Dr. Byrne Perry

1 - Professor P. Garabedian

I - Mr. L. I. Schiff

1 - Dr. S. Kline

1 - Professor E. Y. Hsu

1 Department of Theoretical and Applied Mechanics, College of Engineering, University of IIIinois, Urbana, Illinois, Attn: Dr. J. M. Robertson.

1 Department of Mathematics, Rensselaer Polytechnic Institute, Troy, New York, Attn: Professor R. C. DiPrima.

1 Southwest Research Institute, 8500 Culebra Road, San Antonio 6, Texas, Attn: Dr. H. N. Abramson.

1 Department of Aeronautical Engineering, University of Colorado, Boulder, Colorado, Attn: Professor M. S. Uberoi.

1 Mr. W. R. Wiberg, Chief, Marine Performance Staff, The Boeing Company, Aero-Space Division, P. 0. Box 3707, Seattle 24, Washington.

1 Dr. Beno Sternlicht, Mechanical Technology, Inc., 968 Albany Shaker Road, Latham, New York.

1 Professor J. William Holl, Aeronautical Engineering Department, The Pennsylvania State University, Ordnance Research Laboratory, P. 0. Box 30, University Park, Pennsylvania 16801.

I Science and Technology Division, Library of Congress, Washington, D. C. 20540 . 


$$
\text { a }
$$




\section{DOCUMENT CONTROL DATA - R\&D}

(Security classification of title, body of abstract and indexinB annotation must be entered when the overall report is classified) 1. ORIGINATIN G ACTIVITY (Corporate author)

St. Anthony Falls Hydraulic Laboratory, University of Minnesota 2a. REPORT SECURITY CLASSIFICATION Unclassified

$2 b$, GROUP

3. REPORT TITLE

A NEW FACILITY FOR EVALUATION OF MATERIALS SUBJECT TO EROSION AND

CAVITATION DAMAGE

4. DESCRIPTIVE NOTES (Typo of roport and inclusive dates)
Interim Memorandum
$\begin{array}{ll}\text { 5. AUTHOR(S) (Last namo, first name, initial) } \\ \text { Ripken, John F. } & \text { Crist, Scott D. } \\ \text { Killen, John M. } & \text { Kuha, Roy M. }\end{array}$

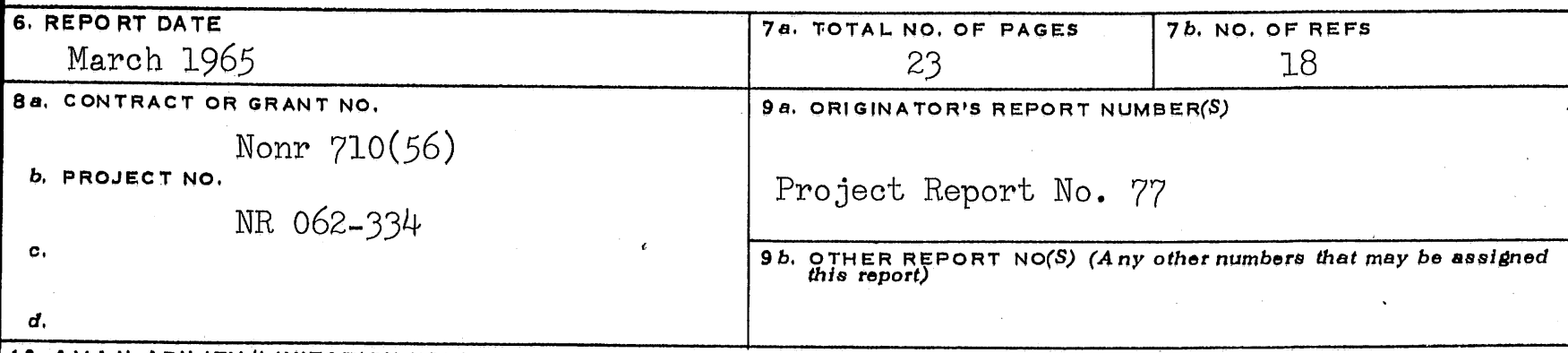

10. AVA ILABILITY/LIMITATION NOTICES

Foreign announcement and dissemination of this report by DDC is not authorized. Not releasible to foreign nationals.

11. SUPPL EMENTARY NOTES

12. SPONSORING MILITARY ACTIVITY

Office of Naval Research

David Taylor Model Basin

13. ABSTRACT

A new type of test facility for simulating accelerated cavitation damage is described. The facility consists of a rotor with a material specimen attached at the periphery in such a manner that there is repeated impact with a column of liquid droplets during high-speed rotation of the specimen. Preliminary tests indicate that erosive weight loss from the specimen is similar in character to that produced by other cavitation damage facilities. A refined ability to control impact conditions permits detailed study of the failure mechanics. 


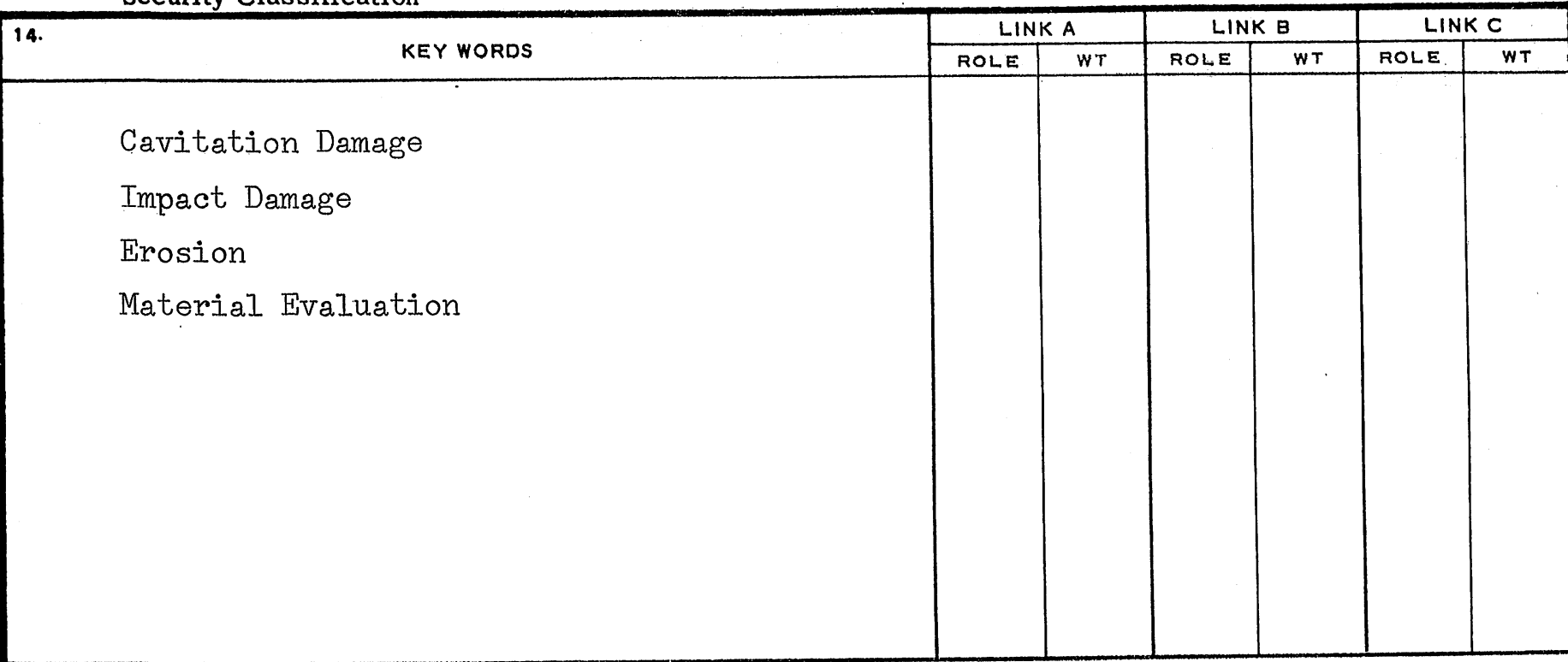

\section{'INSTRUCTIONS}

1. ORIGINATING ACTIVITY: Enter the name and address of the contractor, subcontractor, grantee, Department of Defense activity or other organization (corporate author) issuing the report.

2a. REPORT SECURTY CLASSIFICATION: Enter the overall security classification of the report. Indicate whether "Restricted Data" is included. Marking is to be in accordance with appropriate security regulations.

2b. GROUP: Automatic downgrading is specified in DoD Directive 5200.10 and Armed Forces Industrial Manual. Enter the group number. Also, when applicable, show that optional markings have been us ed for Group 3 and Group 4 as authorized.

3. REPORT TITLE: Enter the complete report title in all capital letters. Titles in all cases should be unclassified. If a meaningful title cannot be selected without classification, show title classification in all capitals in parenthesis immediately following the title.

4. DESCRIPTIVE NOTES: If appropriate, enter the type of report, e.g., interim, progress, summary, annual, or finall.

Give the inclusive dates when a specific reporting period is covered.

5. AUTHOR(S): Enter the name(s) of author(s) as shown on or in the report. Enter last name, first name, middle initial. If military, show rank and branch of service. The name of the principal author is an ahsolute minimum requirement. 6. REPORT DATE: Enter the date of the report as day, month, year; or month, year. If more than one date appears on the report, use date of publication.

7a. TOTAL NUMBER OF PAGES: The total page count should follow normal pagination procedures, i. e., enter the number of pages containing information.

7b. NUMBER OF REFERENCES: Enter the total number of references cited in the report.

8a. CONTRACT OR GRANT NUMBER: If appropriate, enter the applicable number of the contract or grant under which the report was written.

$8 b, 8 c, 88 d$. PROJECT NUMBER: Enter the appropriate military department identification, such as project number, subproject number, system numbers, task number, etc.

9a. ORIGINATOR'S REPORT NUMBER(S): Enter the official report number by which the document will be identified and controlled by the originating activity. This number must be unique to this report.

9b. OTHER REPORT NUMBER(S): If the report has been assigned any other report numbers (either by the originator or by the sponsor), also enter this number(s).

10. AVAIL ABILITY/LIMITATION NOTICES: Enter any limitations on further dissemination of the report, other than those imposed by security classification, using standard statements such as:

(1) "Qualified requesters may obtain copies of this report from DDC."

(2) "Foreign announcement and dissemination of this report by DDC is not authorized."

(3) "U. S. Government agencies may obtain copies of this report directly from DDC. Other qualified DDC users shall request through ."

(4) "U. S. military agencies may obtain copies of this report directly from DDC. Other qualified users shall request through - "

(5) "All distribution of this report is controlled. Qualified DDC users shall request through - "

If the report has been furnished to the Office of Technical Services, Department of Commerce, for sale to the public, indicate this fact and enter the price, if known.

11. SUPPLEMENTARY NOTES: Use for additional explanatory notes.

12. SPONSORING MILITARY ACTIVITY: Enter the name of the departmental project office or laboratory sponsoring (paying $f \circ r$ ) the research and development. Include address.

13. ABSTRACT: Enter an abstract giving a brief and factual summary of the document indicative of the report, even though it may also appear elsewhere in the body of the technical report. If additional space is required, a continuation sheet shall be attached.

It is highly desirable that the abstract of classified reports be unclassified. Each paragraph of the abstract shall end with an indication of the military security classification of the information in the paragraph, represented as $(T S),(S),(C)$, or (U).

There is no limitation on the length of the abstract. However, the suggested length is from 150 to 225 words.

14. KEY WORDS: Key words are technically meaningful terms or short phrases that characterize a report and may be used as index entries for cataloging the report. Key words must be selected so that no security classification is required. Identifiers, such as equipment model designation, trade name, military project code name, geographic location, may be used as key words but will be followed by an indication of technical context. The assignment of links, roles, and weights is optional. 